\title{
Data report: digital core images as data: an example from IODP Expedition 303'
}

\author{
Roy H. Wilkens, ${ }^{2}$ Nancy Niklis, ${ }^{3}$ and Mark Frazer ${ }^{3}$
}

\section{Chapter contents}

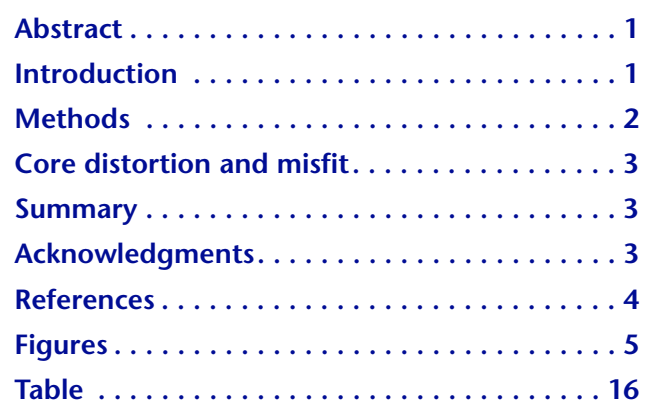

'Wilkens, R.H., Niklis, N., and Frazer, M., 2009. Data report: digital core images as data: an example from IODP Expedition 303. In Channell, J.E.T., Kanamatsu, T., Sato, T., Stein, R., Alvarez Zarikian, C.A., Malone, M.J., and the Expedition 303/306 Scientists, Proc. IODP, 303/306: College Station, TX (Integrated Ocean Drilling Program Management International, Inc.).

doi:10.2204/iodp.proc.303306.201.2009

${ }^{2}$ Hawaii Institute of Geophysics and Planetology, Honolulu HI 96822, USA.

rwilkens@soest.hawaii.edu

${ }^{3}$ Department of Geology and Geophysics, University of Hawaii, Honolulu HI 96822, USA.

\section{Abstract}

Digital core images offer the highest resolution realization of core properties available to scientific investigators. The digital core scanner used aboard the JOIDES Resolution during Integrated Ocean Drilling Program Expedition 303 captured 10 pixels per millimeter of core. The ocean drilling community, however, has been slow to utilize these digital data as other than highly detailed pictures. In this study we illustrate a fast and simple method to extract core images as depth-scaled digital data. These data can then be manipulated through image enhancement to highlight detail not easily recognized in the original image or cores. Other data such as multisensor track core scans can be easily overlain on the images. We use digital core images to examine core distortion by developing sets of tables for five Expedition 303 sites that precisely map features in the site composite to those same features in individual cores from each hole at that site. In general, results show that in $80 \%$ of instances features within the composite section line up to within $35 \mathrm{~cm}$ of the same features in sections not used for the composite.

\section{Introduction}

Routine high-resolution digital imaging of individual core sections began during Leg 198 of the Ocean Drilling Program in 2001. The images collected are of extremely high resolution at $\sim 10$ pixels per millimeter of core. They represent an excellent visual record of a core section soon after it is split and are a welcome addition to the ocean drilling database. These images, however, have not been fully exploited as a valuable source of quantitative data. In this study, we extract from the digital images only the sediment portion of the pictures. The extracted section images are then scaled to a common depth resolution and combined to form compound core images. The intervals of the compound core images used in the composite section are then extracted to form a composite site image.

Images are stored in the Integrated Ocean Drilling Program (IODP) database as three-dimensional matrixes with red, green, and blue (RGB) layers. The images can also be transformed into other color schemes, such as hue, saturation, and lightness (HSL). Full maps or profiles of these properties can be extracted and compared to discrete core analysis data. The images can be color- 
enhanced to highlight features that are not easily seen in the raw data or in the actual cores themselves.

As a demonstration of the use of depth-calibrated digital core images we examined how well the meters composite depth (mcd) scale of features in the composite site section match with the mcd scale of those same features in core that was not used in the composite. We examined 18 holes from five sites (U1304-U1308) cored during Expedition 303. The results suggest that most cores are in reasonable agreement within and outside of the composite.

\section{Methods}

\section{Cutting and scaling the image}

The initial step in the procedure to build a compound image of an entire core is to extract from the digital picture of a core section only that part of the image that is sediment. (We use the term "compound" to avoid "composite," which is associated with the composite depth scale.) Digital core scan images of a $1.5 \mathrm{~m}$ long section are $\sim 16,000$ pixels $\times$ 860 pixels, whereas the core image itself is on the order of 15,000 pixels $\times 700$ pixels within the image. At 15,000 pixels per $1.5 \mathrm{~m}$ long section, the resolution of the digital image is about $0.1 \mathrm{~mm}$. One end of a typical section image is displayed in Figure F1. Note the meter rule across the top of image supplying scale. We use the white cross-hair cursor shown in the figure to mark the top of the cored material. In general, as long as the top of the cored material is within $1 \mathrm{~cm}$ of the top of the core tube we used $0 \mathrm{~cm}$ as the top level of material. A similar procedure is carried out for the lower end of the section, with a provision to mark the extent of missing material because of water content samples taken from the bottom of sections prior to splitting. The section length identified through the cursor and meter rule is checked against the coring table downloaded from the IODP database. Typically, as with the top of the section, the section length in the database is within $1 \mathrm{~cm}$ of the length seen in the image.

Once the horizontal positions of the top and bottom of the sediment in the image have been delineated, a 400 pixel wide swath is cut from the image centered around pixel 500 (see the vertical axis in Fig. F1). The data within this image are then scaled in meters below seafloor (mbsf), the depth to the top of the section extracted from the coring summary. During the scaling process, the subimage is interpolated to a common scaling factor of $0.35 \mathrm{~mm}$ per pixel along the depth axis. This scaling factor is $\sim 1 / 3$ that of the original data and is a trade-off between maximum resolution and the desire to keep the composite core images to a manageable size. Once each section of core has been processed, individual sections are concatenated into a compound core image (Fig. F2). In the figure we have also brightened the image by expanding the color ranges. Image enhancement brings out more subtle layering than is visible in the original images and even the cores themselves.

The process of assembling a compound core image is fast and simple. It takes $<5 \mathrm{~min}$ to process a seven section core and produce the scaled compound image. It is then a simple exercise to plot other sets of data over the image, such as magnetic susceptibility from the multisensor track (MST) (Fig. F3). The scanner used during Expedition 303 was a little too slow to allow these types of plots to be done before sampling and core description was complete, but newer, faster scanning equipment will certainly allow plots such as those in Figure $\mathbf{F} 3$ to be available as individual sections are described.

\section{Hole and site composites}

Compound core images were initially calibrated to mbsf values but were easily shifted to mod using the affine table generated by Splicer, the core correlation program used to develop the composite depth scale. After each core was scaled to mcd, the Splicer splice table was used to copy from compound core images those intervals of the images that were part of the composite site. The subimages were then assembled to produce a composite site image using the mcd scale. Splicer-generated data files from the MST can be overlain on the composite image as well as discrete data such as carbonate content (Fig. F4).

Color images are stored in the computer as three-dimensional matrixes. Raw data from the Expedition 303 core scanner were stored as RGB layers. Our software allowed us to transform the RGB images to HSL images as an alternative color image storage protocol. Profiles of R, G, B, H, S, and L were extracted from the composite site images to facilitate comparison of image data with other discrete data. Each profile represents the average value of the 20 center pixels at each depth point. The carbonate content data displayed over the composite core image in Figure F4 suggest a relationship between higher carbonate values and lighter core colors. We plotted the same carbonate content values along with a profile of $\mathrm{L}$ from the Site U1304 composite core image in Figure F5. Agreement between the two sets of data is apparent and is further illustrated in a cross-plot of carbonate content and corresponding value of L in Figure F6. The majority of the anomalous points in Figure F6 are associated with thick diatomite intervals seen deeper at the site. 


\section{Core to composite correlation}

We displayed each compound core image from Site U1304 versus its assigned mcd depth in Figure F7. A close-up of only the top 25 mcd is shown in Figure F8. By plotting the tops and bottoms of the intervals used to make up the mcd site, it is possible to see how well intervals of core outside the composite agree with those used to form it. For Site U1304 it can be seen in Figure F7 that the composite comes almost exclusively from Holes U1304A and U1304B. The mismatch of Core 303-U1304C-2H is obvious in Figure F8.

Several studies have examined distortion or natural variability core-to-core in deep-sea drilling sediments in the past (e.g., Hagelberg et al., 1995; Pälike et al., 2005). They found that differences in mcd depths of features based on profile data such as MST or color scanners generally amounted to $<20 \mathrm{~cm}$ or so. We performed the same analysis on five sites from Expedition 303 using both profile data and our compound and composite images. Our technique is illustrated in Figure F9. Initially, a compound core image is plotted next to the composite site image. Cursors are used to identify and record tie points between the compound and composite images. Any of the profile data, such as magnetic susceptibility in Figure F9, can be overlain on the image data to aid in choosing tie points. Once an initial set of tie points has been chosen, an interpolated image of the compound core is generated that has been either shrunk or stretched to match the spacing of the tie points. The new image is then plotted next to the composite image. We found that the use of an interpolated image was a great help in refining the placing of tie points and that it was often the case that centimeterscale layering could be perfectly matched between compound and composite core images. The tie points used in Figure F9 are shown in Table T1.

\section{Core distortion and misfit}

The distribution of offsets over the cores from an entire hole is illustrated in Figure F10. In calculating the distribution of offsets, we interpolated the difference between tie points at $5 \mathrm{~cm}$ intervals over the entire depth of the hole, essentially assuming that stretching and compressing of one set of data to the other was evenly distributed between tie points. While this assumption might not be exactly physically correct, the fact that tie points were closely spaced where mismatches occurred minimizes any overall bias it might impose on the data. Hole U1304A contributed much of its section to the site composite (Fig. F7) and is typical of holes that dominate a composite. Hole U1304C represents the opposite extreme of poor agreement between the site composite and the compound core images. The results of the analyses of all of the holes (18) for five sites cored during Expedition 303 are displayed in Figure F11. For eight of the holes, $80 \%-90 \%$ of the features in the compound core images fall with 10 $\mathrm{cm}$ or so of the composite site image depths. For another eight holes, $65 \%-80 \%$ of the compound and composite image features are within $20 \mathrm{~cm}$ of each other. The two outliers in Figure F11 are Holes U1304C and U1308A. Both of these holes were cored during heavy seas, and their cores were not much used in making up the composite for the site. Less than $50 \%$ of their features are within $20 \mathrm{~cm}$ of the composite depths.

We did not attempt in this study to quantify or categorize the nature of the sources of core misfit seen in the data. Although it would be simple to assign depth differences solely to core disturbance, there were numerous instances where this was observably not the case. In particular, it was not unusual to see reasonably uniform layer thicknesses throughout most of a core offset by a single instance of a recognizable layer having a substantially different thickness from one core to the next. Thus, local variability plays an important role in the small differences we see in mcd in different holes. It remains for a follow-on study to determine if there is some regularity in the nature of this variability that might offer insights into the sedimentation process at Expedition 303 sites.

\section{Summary}

Digital image scans of core sections are more than just pretty pictures. They are a relatively new and useful source of high-resolution core data. Images of the sediment can be extracted, depth-scaled, and compared to any other depth-ordered set of data. In this report we have shown that the process can be automated and performed relatively simply. We have used the data to examine differences between cores from different holes at five sites from IODP Expedition 303 and found that most offsets are within 35 $\mathrm{cm}$ of the composite section.

\section{Acknowledgments}

The authors wish to thank the Captain and crew of the JOIDES Resolution and the hard working IODP technical staff aboard during Expedition 303. We 
also thank Tatsuhiko "Tats" Sakamoto for his review of our original manuscript and his helpful comments.

\section{References}

Hagelberg, T.K., Pisias, N.G., Shackleton, N.J., Mix, A.C., and Harris, S., 1995. Refinement of a high-resolution, continuous sedimentary section for studying equatorial Pacific Ocean paleoceanography, Leg 138. In Pisias,

N.G., Mayer, L.A., Janecek, T.R., Palmer-Julson, A., and van Andel, T.H. (Eds.), Proc. ODP, Sci Results, 138: College Station, TX (Ocean Drilling Program), 31-46. doi:10.2973/odp.proc.sr.138.103.1995
Pälike, H., Moore, T., Backman, J., Raffi, I., Lanci, L., Parés, J.M., and Janecek, T., 2005. Integrated stratigraphic correlation and improved composite depth scales for ODP Sites 1218 and 1219. In Wilson, P.A., Lyle, M., and Firth, J.V. (Eds.), Proc. ODP, Sci. Results, 199: College Station, TX (Ocean Drilling Program), 1-41. doi:10.2973/ odp.proc.sr.199.213.2005

Initial receipt: 6 May 2008

Acceptance: 26 April 2009

Publication: 22 July2009

MS 303306-201 
Figure F1. Raw section image showing meter rule along the top and core liner. White cross-hair cursor indicates top of section within liner. Depth in section $(\mathrm{mm})$
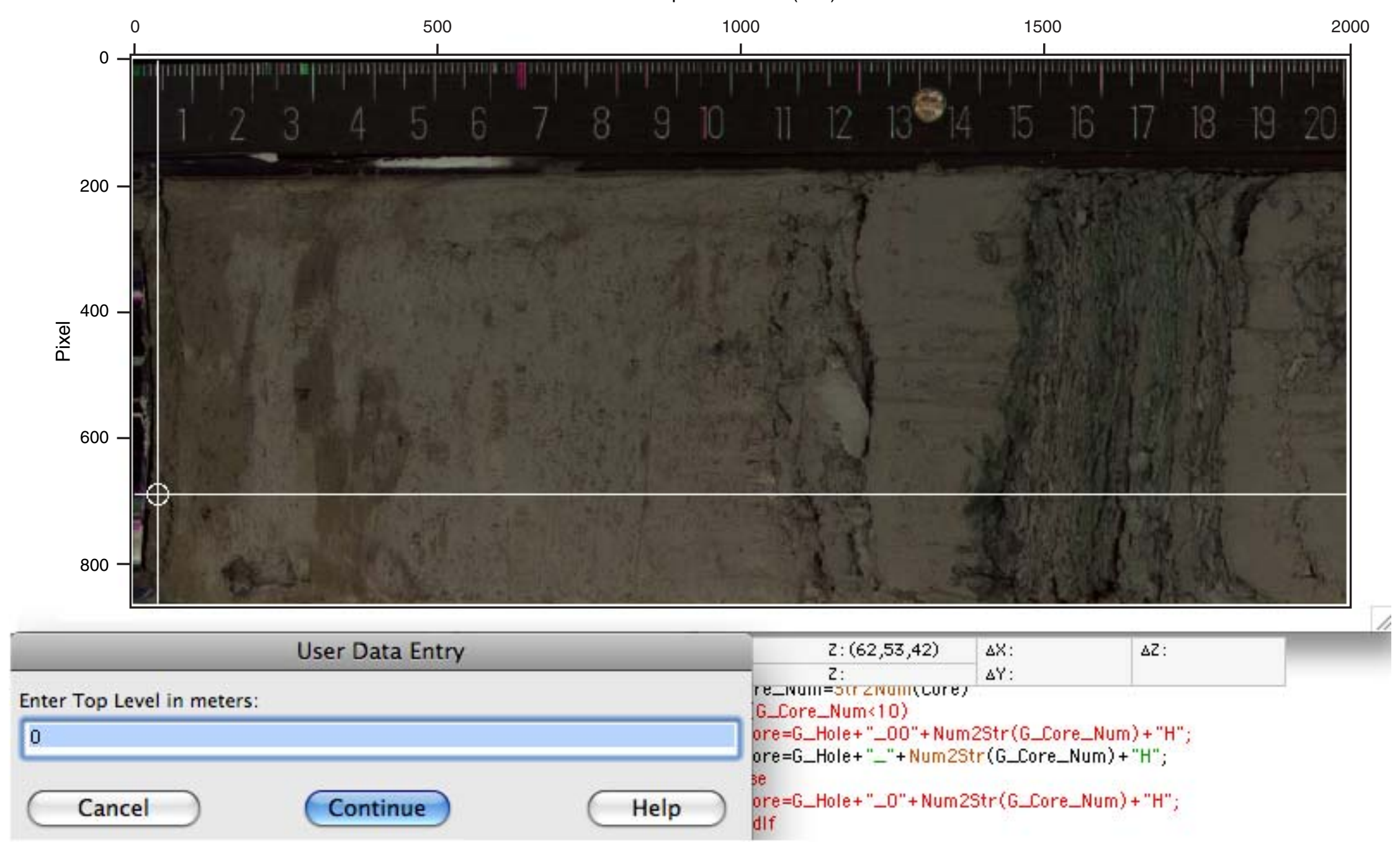
Figure F2. A. Compound image of Core 303-U1304A-4H. B. Image of Section 303-U1304A-4H-4 used in construction of total core image. Images have been brightened to accentuate layering of sediments. Black interval just above $30 \mathrm{mbsf}$ is due to a water content sample being taken from the core.

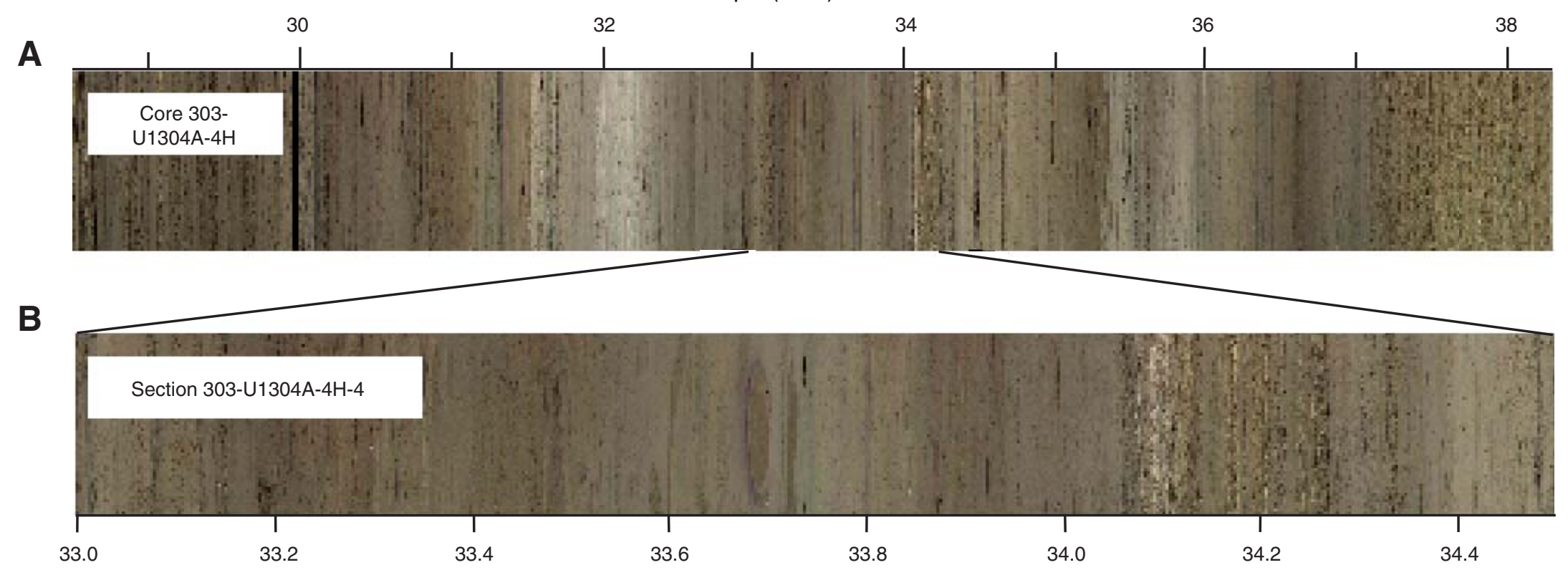


Depth (mbsf)

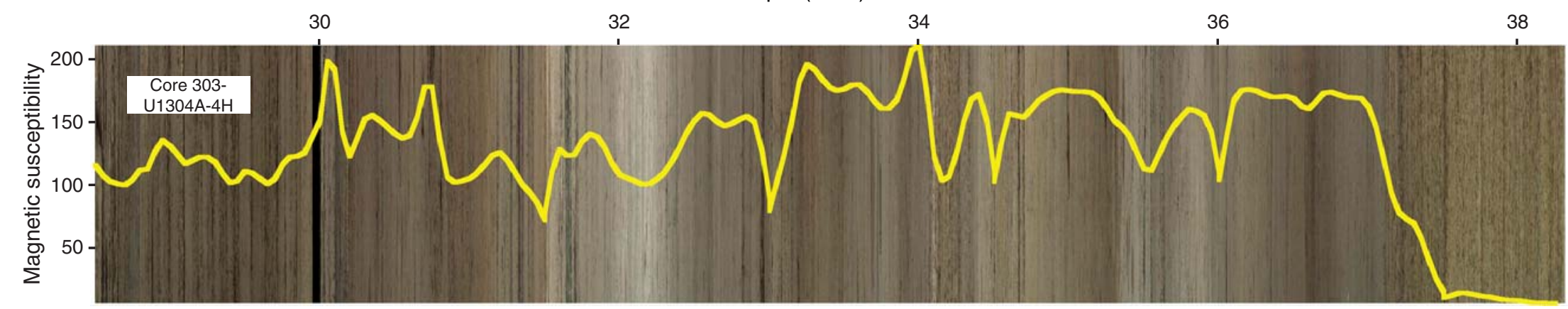


Figure F4. Composite image of Site U1304. Pieces of various compound core images were used to construct composite. Overlain on image are spliced magnetic susceptibility profile and carbonate content values from Hole U1304A corrected to meters composite depth (mcd).

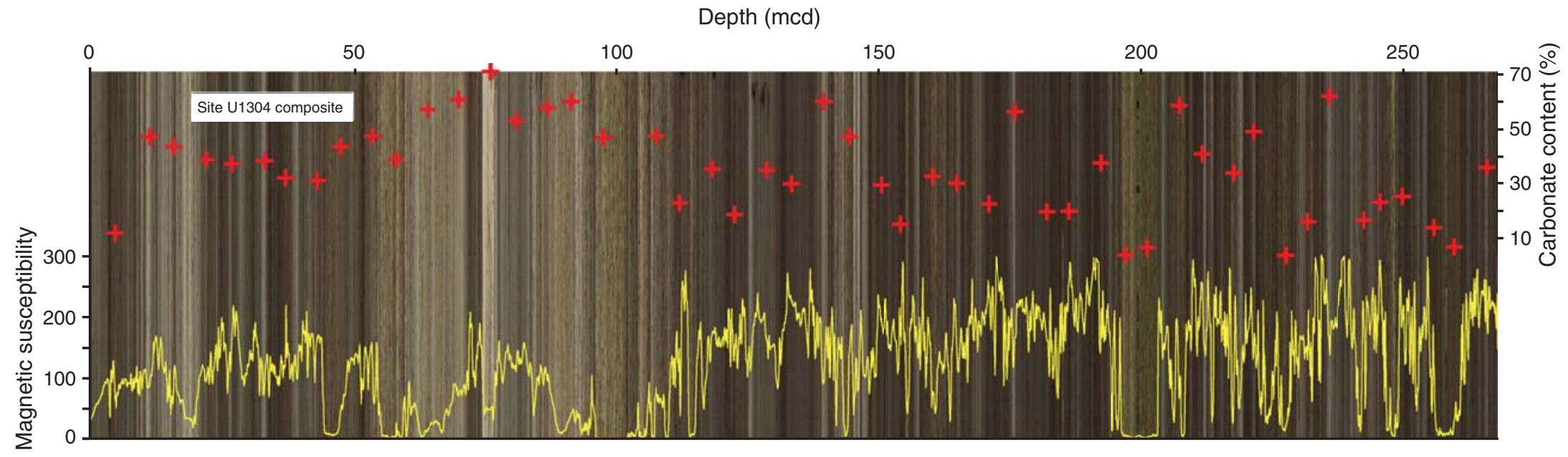


Figure F5. Lightness profile from the Site U1304 composite image with carbonate content from Hole U1304A. Agreement between lightness and carbonate is quite good with a few exceptions. Areas of low carbonate and light color are thick sections of diatoms. mcd = meters composite depth.

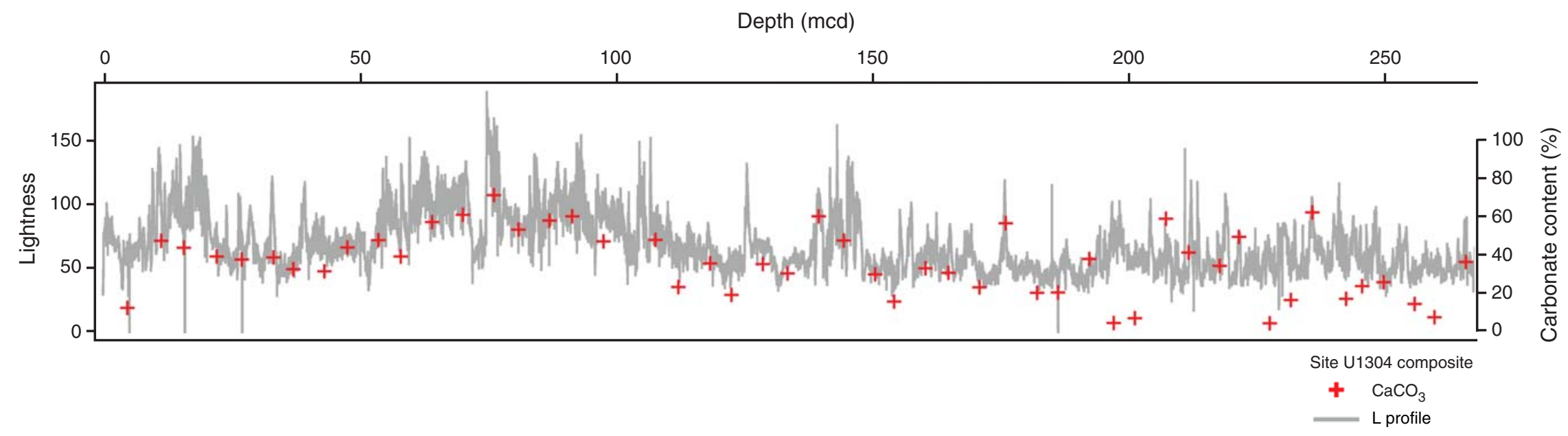


Figure F6. Cross-plot of lightness and carbonate data displayed vs. depth in Figure F5.

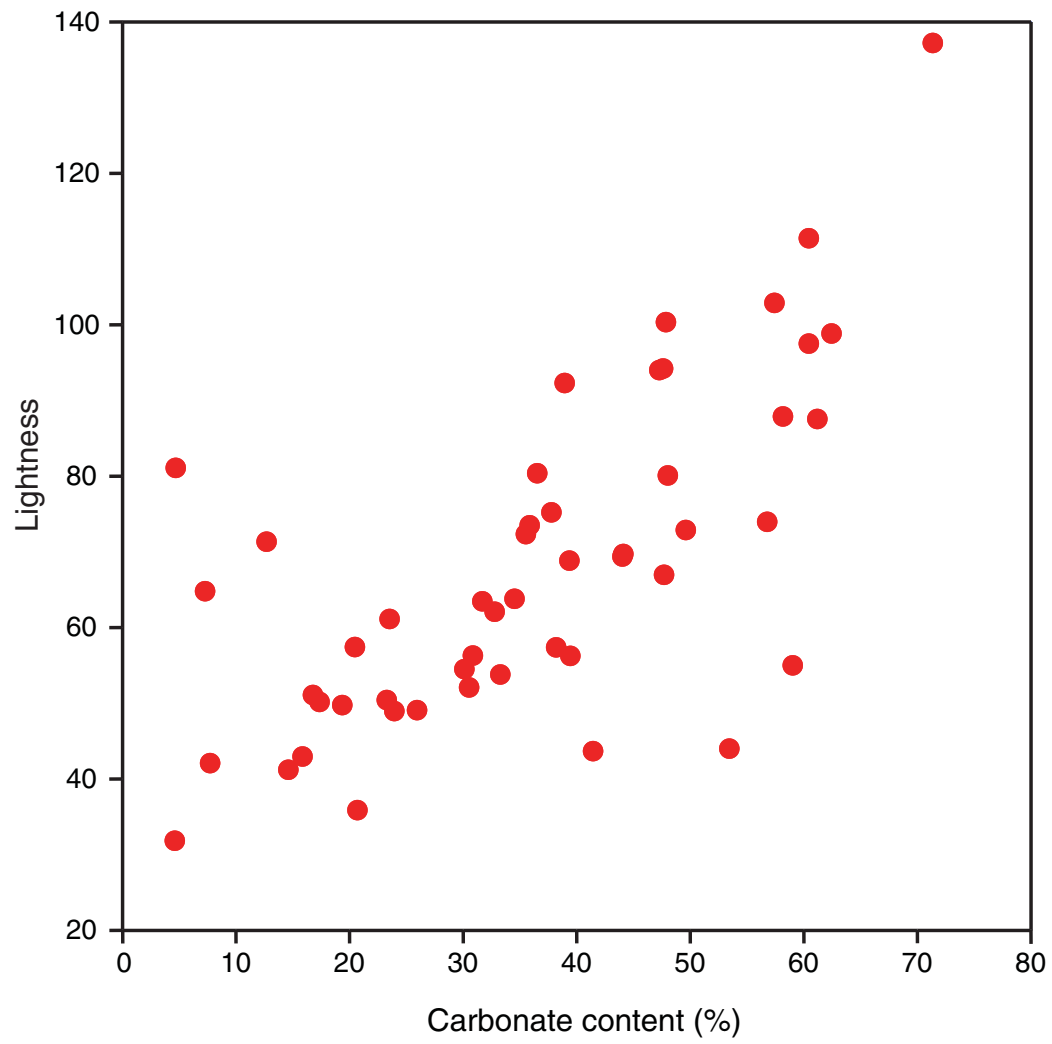


Figure F7. Site U1304 compound core images plotted vs. meters composite depth (mcd). Red bars = top of an interval used in composite depth scale, yellow $=$ bottom of composite depth section.

Depth $(\mathrm{mcd})$

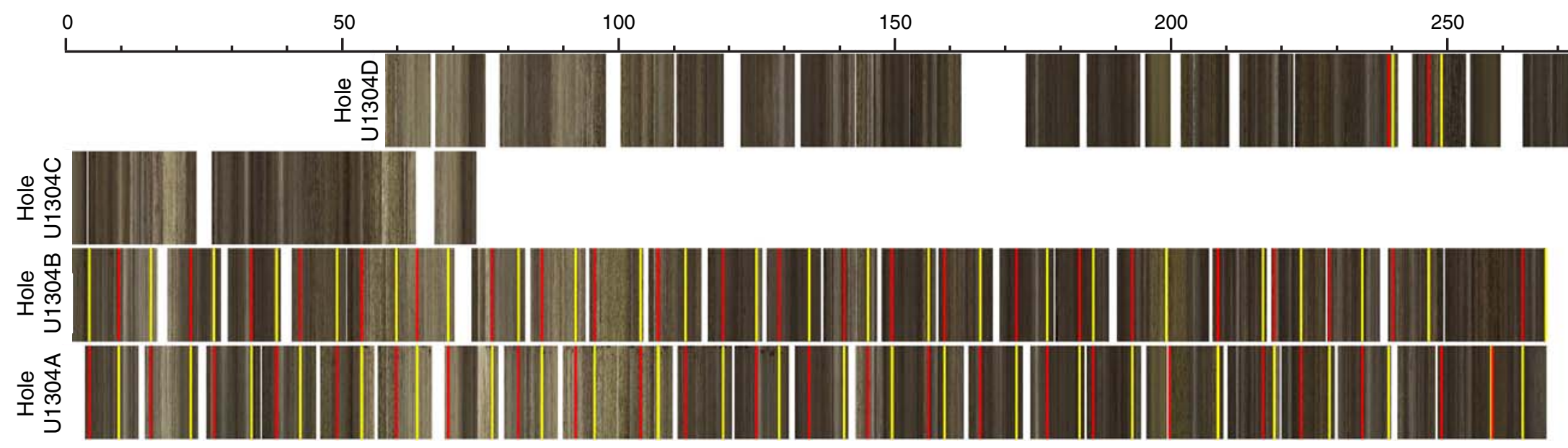


Figure F8. Detail from Figure F7. Red bars = top of an interval used in composite depth scale., yellow = bottom of interval. Note several misalignments between features within and outside of the composite.

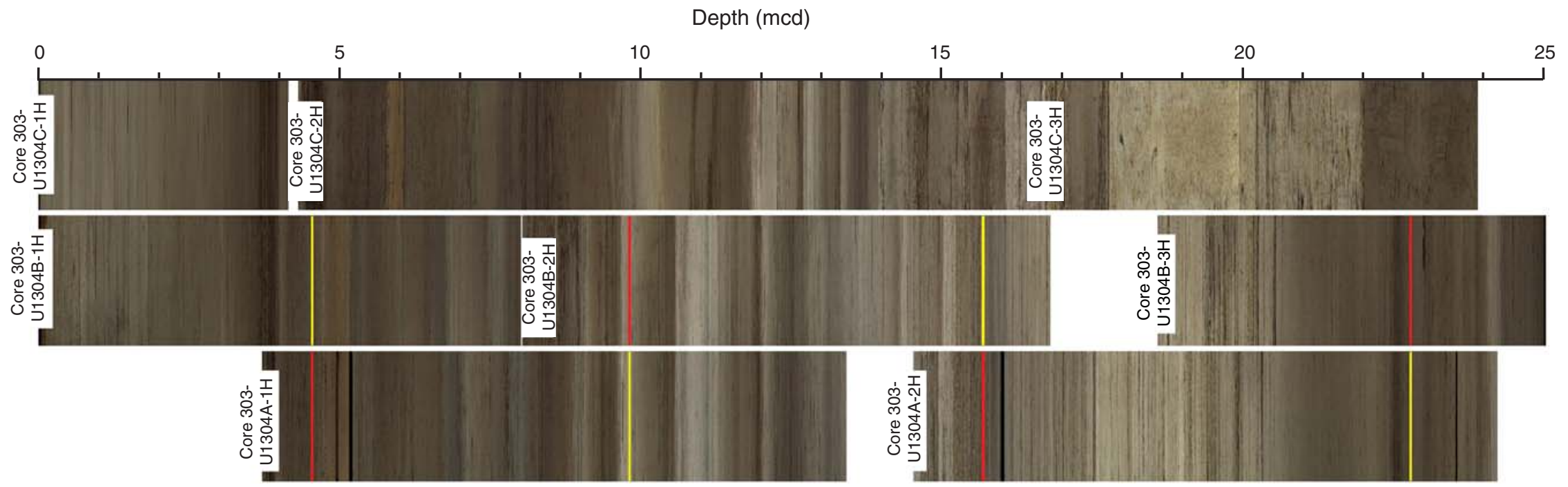


Figure F9. (C) Image of Core 303-U1304C-2H compared to (B) composite site image. Green numbers = tie points. (A) Another view of Core 303U1304C-2H interpolated to match composite image using tie points. Red line = magnetic susceptibility.

Depth $(\mathrm{mcd})$

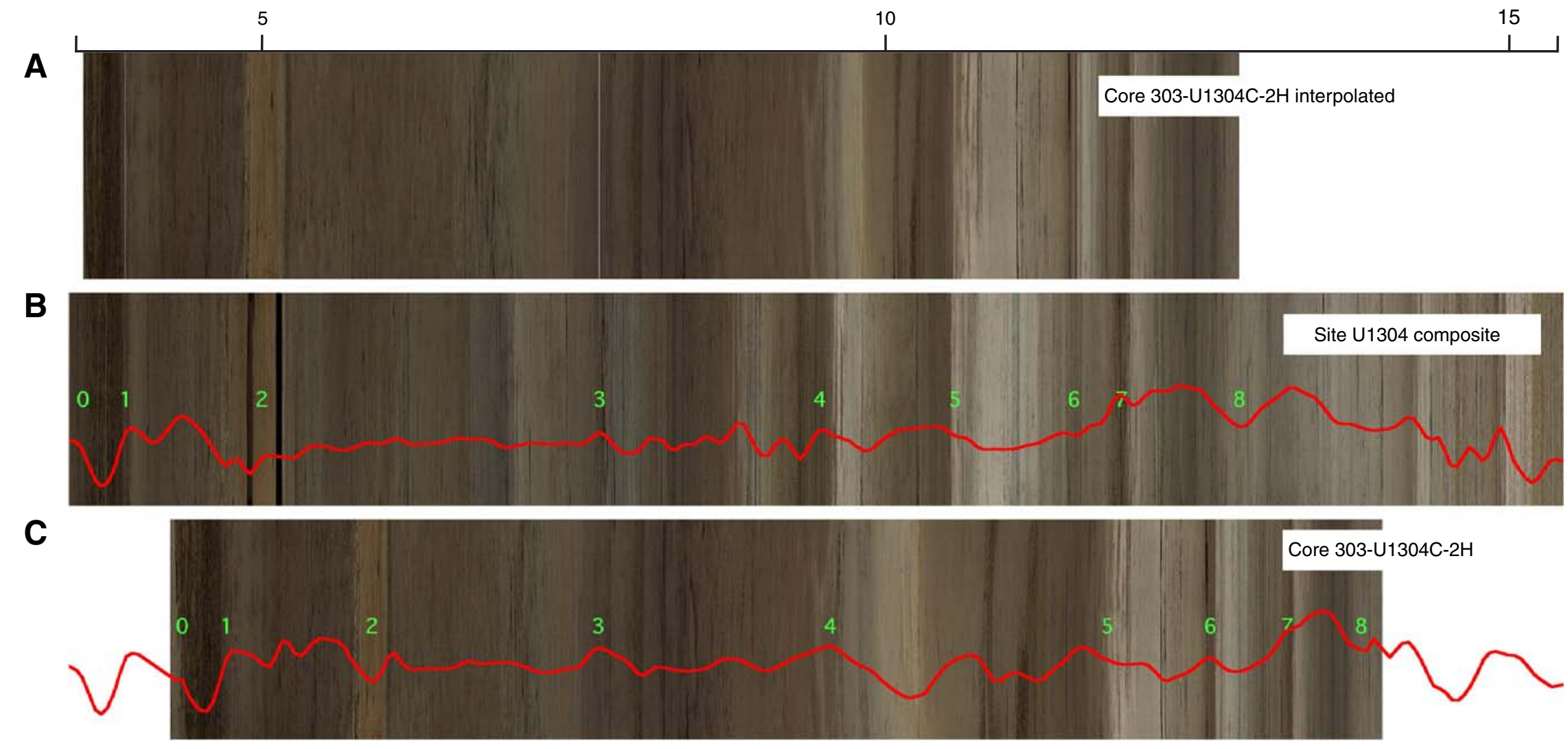


Figure F10. Examples of offset of features in compound core images from composite site images. Hole U1304A is typical of a hole that contributed much of its section to the composite; Hole U1304C is one of the two worst holes in terms of agreement with the composite.
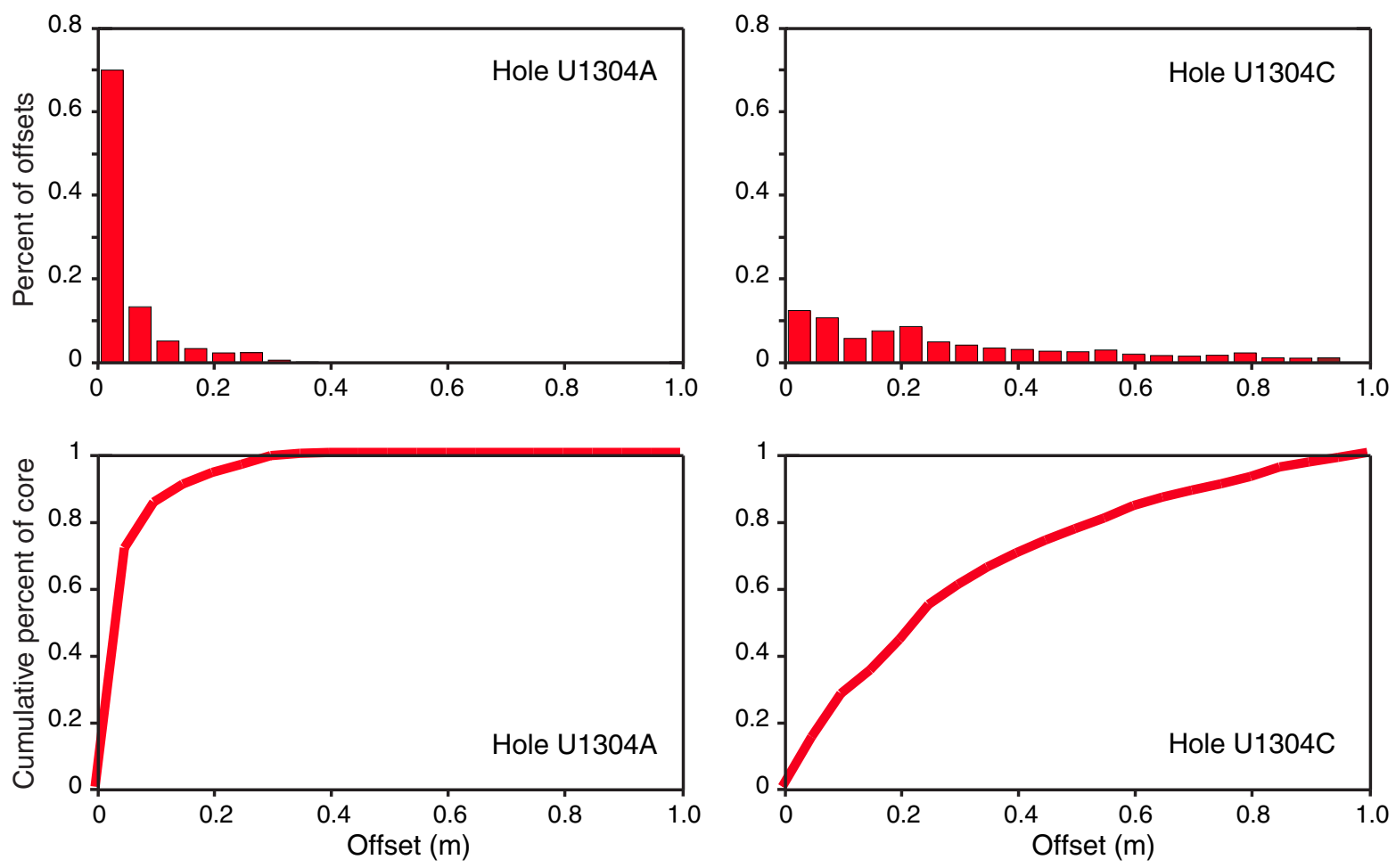


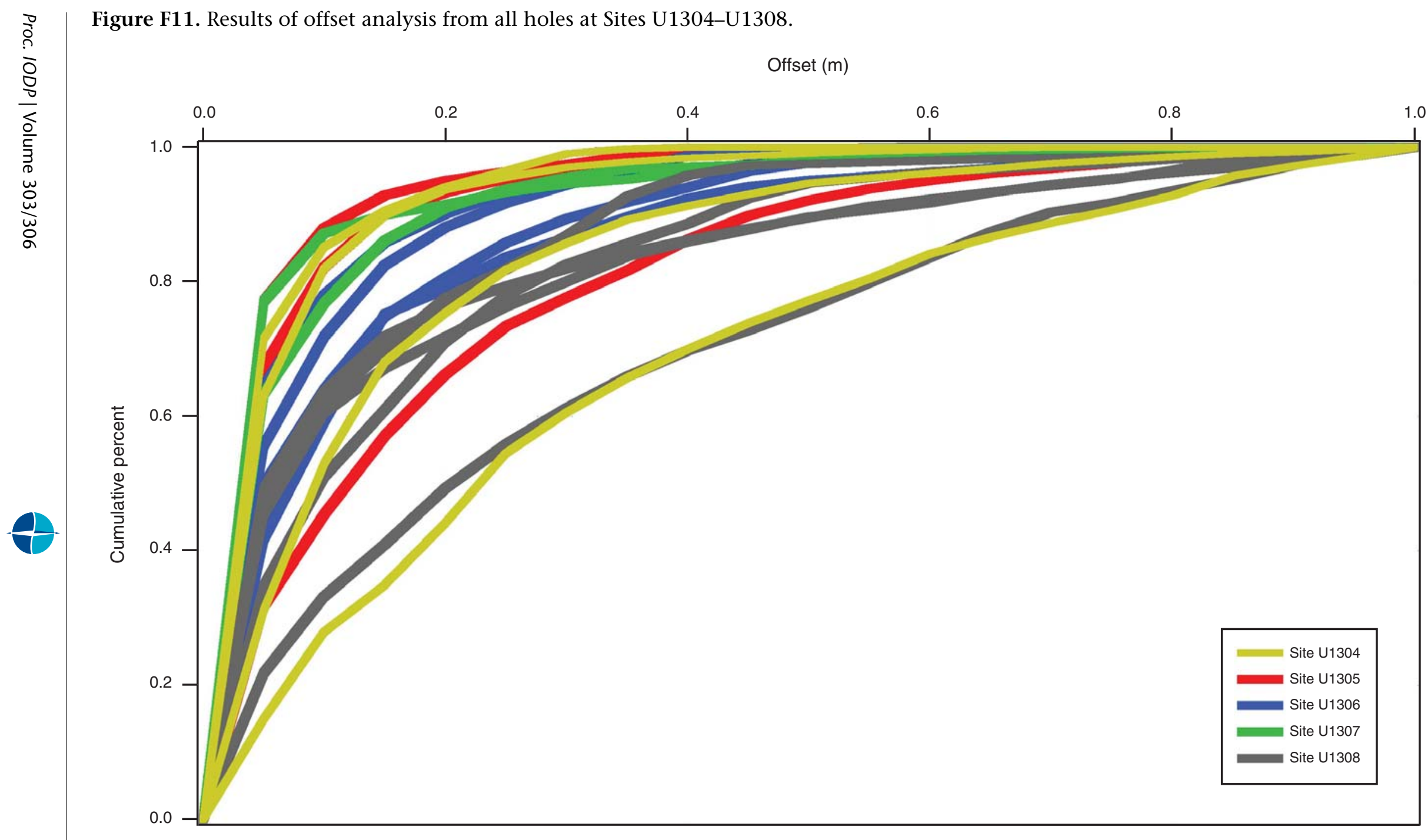


Table T1. Tie points between compound core image and composite site image shown in Figure F9. (See table note.)

\begin{tabular}{cc}
\hline $\begin{array}{c}\text { Core 303- } \\
\text { U1304-2H } \\
\text { (mcd) }\end{array}$ & $\begin{array}{c}\text { Site U1304 } \\
\text { composite } \\
\text { (mcd) }\end{array}$ \\
\hline 4.40 & 3.60 \\
4.75 & 3.94 \\
5.392 & 5.04 \\
7.73 & 7.75 \\
9.59 & 9.51 \\
11.81 & 10.59 \\
12.64 & 11.55 \\
13.26 & 11.93 \\
13.85 & 12.87 \\
\hline
\end{tabular}

Note: $\mathrm{mcd}=$ meters composite depth. 